\title{
Design and Characterization of Mucoadhesive Microspheres for Gastro- Retentive Delivery of Famotidine Hydrochloride
}

\section{Shanthi Priya $\mathrm{CH}^{*}$}

Department of Pharmaceutical Sciences, Srikrupa Institute of Pharmaceutical Sciences, Osmania University, Hyderabad, Telangana, India

\begin{abstract}
This article illustrates the Design and Characterization of Mucoadhesive microspheres with Famotidine Hydrochloride as drug for Gastro-Retention of drug release. The microspheres were prepared by the lon Gelation method and Thermal Cross Linking Method. In Ion Gelation method sodium alginate is used as a release controlling biopolymer and Calcium chloride is acts as hygroscopic cross linking agent. In Thermal Cross Linking Method egg albumin is used as binding agent and a Thermal energy is used as cross linking property. The characteristics like shape and structure of prepared microspheres by Optical microscopy and scanning electron microscopy, respectively. In vitro drug release studies were done and drug release was evaluated. Effect on the Mucoadhesion, drug Entrapment Efficiency of microspheres and Drug release were observed. The prepared microspheres exhibited prolonged drug release $(17 \mathrm{hrs})$ the mean particle size increased as the concentration of sodium alginate increased, as the egg albumin concentration increases the Mucoadhesion increased and the drug release rate decreased at higher concentration of sodium alginate. Significant effect of the Encapsulation Efficiency of microspheres was observed. In vitro studies demonstrated the Gastro retentive delivery of drug from the microspheres.
\end{abstract}

Keywords: Mucoadhesive microspheres; Famotidine; In vitro release; Gastric residence time

\section{Introduction}

Famotidine is a competitive histamine H2-receptor antagonist. Their principal pharmacodynamics outcome is the inhibition of gastric secretion. Famotidine is used as for the treatment of peptic ulcer disease (PUD) and gastro esophageal reflux disease (GERD). Famotidine binds competitively to $\mathrm{H} 2$-receptors located on the basolateral membrane of the parietal cell, blocking histamine influences. This competitive inhibition outcome in lowered basal and nocturnal gastric acid secretion and reduction in gastric quantity, acidity. The bioavailability of oral doses of famotidine is forty-45\%. 1/2-lifestyles are 2.5-3.5 hours. Oral administration is probably the most suitable and desired manner of any drug delivery to the systematic circulation. Medicines which might be effectively absorbed from gastrointestinal tract (GIT) and have quick half of-lives are eliminated rapidly from the systemic circulation. Common dosing of those medications is required to attain suitable therapeutic activity. To avoid this quandary, the progress of oral sustained-controlled liberate formulations is an attempt to release the drug slowly into the gastrointestinal tract (GIT) and preserve an effective drug awareness within the systemic circulation for a very long time. To formulate a orally administered controlled liberate dosage type, it is fascinating to obtain lengthen gastric residence time through the drug delivery. Gastro retentive drug supply is a process to extend gastric time, thereby focusing on site-precise drug unlock in the higher gastrointestinal tract (GIT) for nearby or systemic results [1-10].

\section{Materials and Method}

Famotidine was gift sample from SMS Pharmaceuticals Limited Hyderabad. Andhra Pradesh. Egg albumin, sodium alginate, Liquid paraffin (light), Calcium chloride, Tweens 80 purchased from S.D. Fine Chemicals Limited (Hyderabad) the entire chemical were of analytical grade and double distilled water used throughout the experiment.

\section{Formulation of microspheres}

Microspheres with drug (famotidine Hydrochloride) are prepared by the Ion Gelation and Thermal Cross Linking Method. F1 - F4 are prepared by Thermal Cross Linking Method. F5 - F8 are prepared by Ion Gelation Method.

\section{Thermal cross linking method}

Mucoadhesive microspheres of Famotidine Hydrochloride was prepared by thermal cross linking method. $0.4 \%$ of Tweens 80 was added to $100 \mathrm{~mL}$ of light liquid paraffin and it was heated to $70^{\circ} \mathrm{C}$ till tweens 80 was completely dissolved. It was cooled to room temperature. Prepare $10 \% \mathrm{~W} / \mathrm{V}$ solution of egg albumin and drug solution. Add the solution containing egg albumin and drug (Famotidine) to previously cooled Light Liquid Paraffin. Stir it with mechanical stirrer for 10min and heat it to $95^{\circ} \mathrm{C}$ for $10-15 \mathrm{~min}$. We can see the formation of microspheres. The beads so prepared were collected by decantation, washed with water. Then it was dried over night to become hard microspheres. The process was applied to 4 different formulations by using varying proportions of egg albumin (i.e., F1-F4) [11-15].

\section{Ion gelation method}

Accurately weighed about $10 \%$ of sodium alginate $20 \%$ of egg albumin and kept aside, then it was dispersed in $100 \mathrm{ml}$ of distilled water by using magnetic stirrer at $40^{\circ} \mathrm{C}$. Then after complete dispersion, added accurately $100 \mathrm{mg}$ of Famotidine Hydrochloride then the stirring was continued until complete and uniform dispersion was obtained. Then the Calcium chloride solution was prepared by dispersing the 5 gm of Calcium chloride powder in $100 \mathrm{ml}$ of distilled water by heating at $40^{\circ} \mathrm{C}$.

*Corresponding author: Shanthi Priya $\mathrm{CH}$, Department of Pharmaceutical Sciences, Srikrupa Institute of Pharmaceutical Sciences, Osmania University, Hyderabad, Telangana, India, E-mail: shanthipriyapharma@gmail.com

Received: April 21, 2015; Accepted: April 30, 2015; Published: May 07, 2015

Citation: Shanthi Priya CH (2015) Design and Characterization of Mucoadhesive Microspheres for Gastro-Retentive Delivery of Famotidine Hydrochloride. J Bioengineer \& Biomedical Sci 5: 153. doi:10.4172/2155-9538.1000153

Copyright: (c) 2015 Shanthi Priya $\mathrm{CH}$. This is an open-access article distributed under the terms of the Creative Commons Attribution License, which permits unrestricted use, distribution, and reproduction in any medium, provided the original author and source are credited. 
The resulting bubble free dispersion was added manually drop wise with a $5 \mathrm{ml}$ syringe ( 22 gauze needle) into $100 \mathrm{ml}$ of ( $5 \% \mathrm{w} / \mathrm{v}$ ) calcium chloride solution $\left(\mathrm{CaCl}_{2}\right)$ and stirred in a $250 \mathrm{ml}$ beaker. The gelation time of $15 \mathrm{~min}$ was allowed to complete the curing reaction and produce spherical and rigid microspheres. The beads so prepared were collected by decantation, washed with water and dried in hot air oven at $60^{\circ} \mathrm{C}$ for 2 hours. The process was applied to 4 different formulations by using varying proportions of egg albumin and sodium alginate (i.e., F5-F8) (Table 1).

\section{Characterization of Formulation}

\section{Production yield}

The dried microspheres of each batch are weighed separately and percentage yield is calculated by using following equation.

$$
\text { Percentage yield }=\frac{\text { Practical weight }}{\text { Theoretical weight }} \times 100
$$

\section{Estimation of drug content}

$50 \mathrm{mg}$ of muco adhesive microspheres were weighed and powdered. This was dissolved or extracted in methanol in $100 \mathrm{ml}$ volumetric flask and made up to volume. The solution was shaken occasionally for $1 \mathrm{~h}$ and filtered. From this $1 \mathrm{ml}$ of solution was diluted to $100 \mathrm{ml}$ with $\mathrm{pH}$ 1.2 buffer solution in $100 \mathrm{ml}$ volumetric flask. The drug content was analyzed by measuring absorbance in a UV spectrophotometer at 265 $\mathrm{nm}$ using $\mathrm{pH} 1.2$ phosphate buffer as blank. The studies were carried out in triplicate [16-18].

\section{Drug entrapment efficiency or incorporation efficiency}

To determine the drug entrapment efficiency or incorporation efficiency the microspheres were crushed in glass mortar and powered, then suspended in $10 \mathrm{ml}$ of methanol, after $24 \mathrm{hrs}$ the solution was filtered and filtrate was analyzed for drug content. The drug incorporation efficiency was calculated by the following formula:

$$
\text { Incorporationefficiency }=\frac{b}{a} \times 100
$$

$\mathrm{b}=$ calculated amount of drug present in the formulation,

$\mathrm{a}=$ theoretical amount of drug present in the formulation

\section{Morphology and particle size determination}

The size was measured using an optical microscope, and the mean particle with the help of a calibrated ocular meter.

a) Effect of Stirring Speed on particle size: The effect of stirring speed on the particle size was determined at $500 \mathrm{rpm}$ and $1000 \mathrm{rpm}$.

b) Surface morphology/Scanning Electron Microscopy (SEM): The external morphology of the microspheres was studied by scanning electron microscopy using apparatus Philip 505.

\section{In vitro wash-off test}

The mucoadhesive property of microspheres was evaluated by an in vitro adhesion testing method known as wash-off method. Freshly excised piece of intestinal mucosa $(2 \times 2 \mathrm{~cm})$ from albino rat were mounted onto glass slides $(3 \times 1$ inch) with cyanoacrylate glue. Two glass slides were connected with a suitable support, about 50 microspheres were spread on to each wet rinsed tissue specimen and immediately thereafter the support was hung onto the arm of a USP tablet disintegrating test machine. When the disintegrating test machine was operated, the tissue specimen was given slowly, regular up and down moment in the test fluid $(500 \mathrm{ml} \mathrm{pH} 1.2$ phosphate buffer) maintained at $37^{\circ} \mathrm{C}$. At the end of $30 \mathrm{~min}, 1 \mathrm{~h}$, and hourly intervals up to $8 \mathrm{~h}$, the numbers of microspheres adhering to tissue were counted.

Mucoadhesion $=$ (no. of microspheres adhered/no. of microspheres applied) $\times 100$

\section{In-vitro drug release data and profiles}

The prepared formulation was evaluated for in-vitro release by USP dissolution apparatus 1 at $50 \mathrm{rpm}$ and at $37^{\circ} \mathrm{C}$ temperature in order to determine $100 \%$ drug release. To evaluate microspheres containing famotidine were exposed to $900 \mathrm{ml}$ of $\mathrm{HCl}$ ( $\mathrm{pH}$ 1.2). The samples were collected in pre-determined time intervals. Famotidine concentrations were determined by UV at $265 \mathrm{~nm}[19,20]$.

\section{Result and Discussion}

The mucoadhesive microspheres of sodium alginate and egg albumin prepared by Ion Gelation and Thermal cross linking method. The polymer sodium alginate was selected to control the release rate and egg albumin as a mucoadhesive polymer. Both are biodegradable and mucoadhesive polymer. The formulation of the present microspheres was based on the solubility behavior of both polymers. Eight Formulations F1-F8 were formulated by varying concentration of sodium alginate and egg albumin (Table 1), to study effect of release of famotidine from the microspheres and effect of polymer concentration on the size, percentage mucoadhesion, drug entrapment efficiency. The particle size and surface morphology was determined with the help of optical microscope and Scanning Electron microscope.

To investigate the effect of release of famotidine from the microspheres eight batches F1-F8 were prepared. The drug release prolonged to $17 \mathrm{hrs}$ in formulation F5.

\section{Product yield:}

The results of product yields are shown in Table 2. The percentage yield of formulations was in the range of $86.15 \pm 0.3$ to $95.56 \pm 0.31$. The product yield was manageable with little loss of drug during the formulation stage (Table 2).

\section{Estimation of drug Content}

The results of drug content are shown in Table 3. The percentage drug content of formulations were in the range of $95.21 \pm 0.45$ to 98.65 \pm 0.31 . The low SD and CV value indicates uniform distribution of drug within the various batches of microspheres prepared. The drug content results suggest a negligible loss of drug during the formulation stage (Table 3).

\section{Encapsulation efficiency}

Encapsulation efficiency of all the formulations is presented in the Table 4 . The percentage encapsulation efficiency of set- 1 formulations were in the range of $83.32 \pm 0.11$ to $98.16 \pm 0.45$. The results suggest encapsulation efficiency depend upon concentration of sodium alginate used in the formulation. The encapsulation efficiency is increased progressively with increase in the concentration of sodium alginate. This could be attributed due to formation of larger microspheres with increasing concentration of sodium alginate, thus entrapping more 


\begin{tabular}{|c|c|c|c|c|c|c|c|c|}
\hline \multirow{2}{*}{$\begin{array}{l}\text { Ingredients } \\
\text { (in \%w/v) }\end{array}$} & \multicolumn{8}{|c|}{ Formulation Code } \\
\hline & F1 & F2 & F3 & F4 & F5 & F6 & F7 & F8 \\
\hline Egg albumin & 5 & 10 & 15 & 20 & 20 & 20 & 20 & 20 \\
\hline Sodium alginate & - & - & - & - & 10 & 5 & 3 & 1 \\
\hline Calcium chloride & - & - & - & - & 5 & 5 & 5 & 5 \\
\hline Light liquid paraffine & 100 & 100 & 100 & 100 & - & - & - & - \\
\hline Tween 80 & 0.4 & 0.4 & 0.4 & 0.4 & - & - & - & - \\
\hline Purified water & Q.S & Q.S & Q.S & Q.S & Q.S & Q.S & Q.S & Q.S \\
\hline Drug(mg) & 100 & 100 & 100 & 100 & 100 & 100 & 100 & 100 \\
\hline
\end{tabular}

Table 1: Shows various formulations.

\begin{tabular}{|c|c|}
\hline Formulation & Product yield \pm SD \\
\hline F1 & $86.15 \pm 0.3$ \\
\hline F2 & $88.57 \pm 0.21$ \\
\hline F3 & $89.25 \pm 0.5$ \\
\hline F4 & $89.46 \pm 0.78$ \\
\hline F5 & $95.56 \pm 0.31$ \\
\hline F6 & $91.9 \pm 0.46$ \\
\hline F7 & $94.18 \pm 0.83$ \\
\hline F8 & $93.29 \pm 0.87$ \\
\hline \multicolumn{2}{|c|}{ Table 2: Product yield. } \\
\hline
\end{tabular}

\begin{tabular}{|c|c|c|c|}
\hline Formulation & $\begin{array}{c}\text { Theoretical } \\
\text { drug content(mg) }\end{array}$ & $\begin{array}{c}\text { Practical } \\
\text { drugcontent(mg) }\end{array}$ & $\begin{array}{c}\text { \% Drug content } \\
\mathbf{\pm} \text { SD }\end{array}$ \\
\hline F1 & 40 & 39.61 & $98.43 \pm 0.46$ \\
\hline F2 & 40 & 39.54 & $98.16 \pm 0.45$ \\
\hline F3 & 40 & 39.53 & $98.12 \pm 0.54$ \\
\hline F4 & 40 & 39.23 & $96.92 \pm 0.25$ \\
\hline F5 & 40 & 39.66 & $98.65 \pm 0.31$ \\
\hline F6 & 40 & 39.4 & $97.62 \pm 0.47$ \\
\hline F7 & 40 & 38.8 & $95.21 \pm 0.45$ \\
\hline F8 & 40 & 39.15 & $96.62 \pm 0.62$ \\
\hline
\end{tabular}

Table 3: Drug content.

\begin{tabular}{|c|c|}
\hline Formulation & Microencapsulation efficiency $\mathbf{S}$ SD \\
\hline F1 & $83.32 \pm 0.11$ \\
\hline F2 & $84.11 \pm 0.32$ \\
\hline F3 & $85.02 \pm 0.23$ \\
\hline F4 & $85.65 \pm 0.44$ \\
\hline F5 & $98.16 \pm 0.45$ \\
\hline F6 & $96.81 \pm 0.35$ \\
\hline F7 & $96.92 \pm 0.25$ \\
\hline F8 & $93.23 \pm 0.21$ \\
\hline \multicolumn{2}{|c|}{ Table 4: Encapsulation efficiency. } \\
\hline
\end{tabular}

amount of drug (Table 4).

\section{Morphology and Particle size Determination}

\section{Effect of stirring speed on particle size}

The size analysis of microspheres is carried out by optical microscope. The sizes of microspheres were in the range of 20-90 microns. The size of microspheres is depending upon concentration of sodium alginate used in the formulation. The increase in size of microspheres was observed with increase in concentration of sodium alginate. This could be due to increase in viscosity of the polymeric dispersion, which eventually lead to formation of bigger particle during ionic gelation. The results of the particle size of many of the formulations were in the limits and comply with the standards (Table 5).

\section{Scanning electron microscopy}

Scanning electron microscopy was used to know surface morphology of microspheres. The SEM photographs of F5 revealed that microspheres were spherical, discrete. The outer surface of microspheres was coarse rough texture, with few pores, mild cracks and completely covered with coat materials (Figures 1-3).

\section{In vitro wash off test}

The mucoadhesion is a phenomenon in which two materials, at least one of which is biological are held together by means of interfacial force. The Table 6 shows in vitro mucoadhesion data of mucoadhesive microspheres carried out with everted rat intestinal mucosa in presence of $\mathrm{pH}$ 1.2. The percentage of microspheres retained on everted intestinal mucosa after $6 \mathrm{~h}$ in set- 1 formulations were found in the range of 71-55. The overall results suggest that concentration and type of mucoadhesive polymer doesnot show much more difference in the mucoadhesive property (Table 6).

\section{In-vitro drug release data and profiles}

The dissolution conditions used for studying the drug release from the mucoadhesive microspheres of famotidine were:

Apparatus : USP Type 1 (basket)

Agitation speed (rpm) : 50

Medium : $0.1 \mathrm{~N} \mathrm{HCl}(\mathrm{pH} 1.2), 900 \mathrm{ml}$

Dissoloution volume : $900 \mathrm{ml}$

Temperature : $37.0 \pm 0.5 \mathrm{C}$

Time : $0,0.25,0.5,1,3,5,7,9,11,13,15$ and $17 \mathrm{hrs}$

Wavelength : $265 \mathrm{~nm}$

(i) Release profiles of formulations containing egg albumin: (Table 7)

All the values are represented as Mean $\pm \operatorname{SD}(n=3)$ (Table 8, Figures 4 and 5).

\section{Kinetic Data Analysis}

\section{Kinetic data/Model fitting}

The formulations having maximum release were selected. The result are exhibited in table and plotted in four modes of data treatments.

1) Percentage of drug release versus time.

2) Log percentage of drug remained versus time. 
Citation: Shanthi Priya CH (2015) Design and Characterization of Mucoadhesive Microspheres for Gastro-Retentive Delivery of Famotidine Hydrochloride. J Bioengineer \& Biomedical Sci 5: 153. doi:10.4172/2155- 9538.1000153

Page 4 of 6

\begin{tabular}{|c|c|}
\hline Formulation & Particle size(microns) \\
\hline F1 & $40-60$ \\
\hline F2 & $20-80$ \\
\hline F3 & $50-70$ \\
\hline F4 & $30-40$ \\
\hline F5 & $30-80$ \\
\hline F6 & $50-60$ \\
\hline F7 & $60-80$ \\
\hline F8 & $70-90$ \\
\hline
\end{tabular}

Table 5: Particle Size.

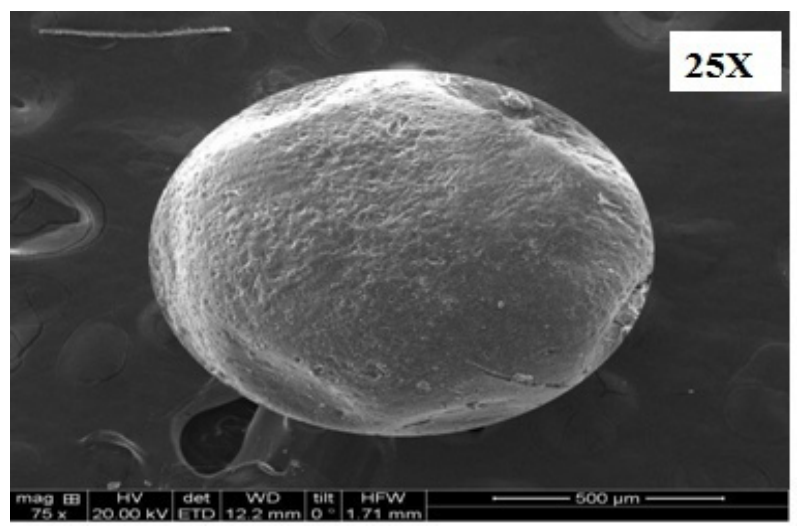

Figure 1: Scanning electron micrographs of F5 formulation.

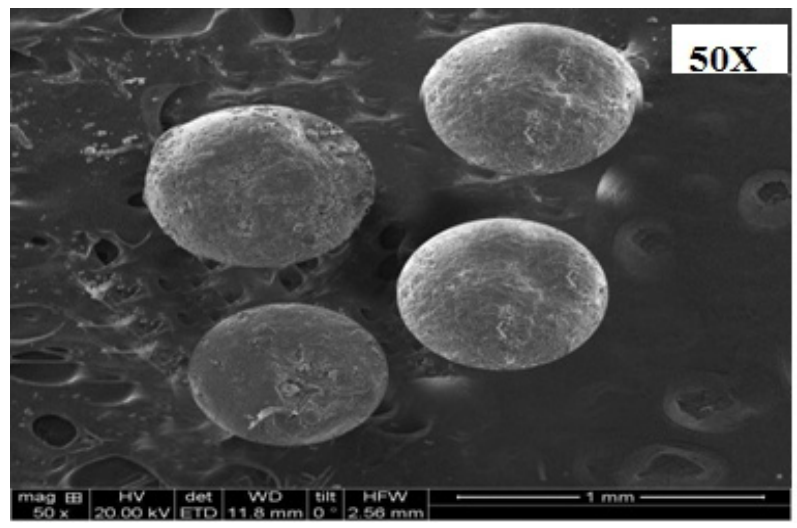

Figure 2: Scanning electron micrographs of F5 formulation.

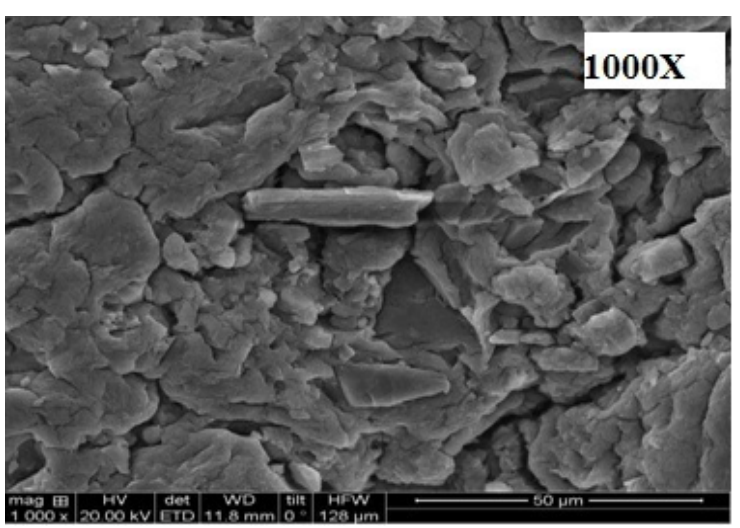

Figure 3: Scanning electron micrographs of F5 formulation.

\begin{tabular}{|l|l|l|l|l|l|l|}
\hline Formulation & \multicolumn{6}{|c|}{ Percentage of microspheres adhering to tissue at different } \\
time interval (h) \\
\hline F1 & 50 & 96 & 88 & 79 & 68 & 68 \\
\hline F2 & 50 & 93 & 82 & 75 & 67 & 67 \\
\hline F3 & 50 & 96 & 85 & 77 & 65 & 65 \\
\hline F4 & 50 & 88 & 80 & 64 & 60 & 60 \\
\hline F5 & 50 & 94 & 83 & 74 & 71 & 71 \\
\hline F6 & 50 & 89 & 74 & 66 & 61 & 61 \\
\hline F7 & 50 & 86 & 74 & 58 & 55 & 55 \\
\hline F8 & 50 & 91 & 78 & 70 & 65 & 62 \\
\hline
\end{tabular}

Table 6: In vitro wash off test.

\begin{tabular}{|c|c|c|c|c|}
\hline Time(h) & F1 & F2 & F3 & F4 \\
\hline 0 & 0 & 0 & 0 & 0 \\
\hline 0.25 & $26.28 \pm 0.36$ & $22.5 \pm 0.36$ & $23.8 \pm 0.54$ & $7.94 \pm 0.54$ \\
\hline 0.5 & $35.2 \pm 0.21$ & $29.23 \pm 0.41$ & $28.4 \pm 0.29$ & $17.86 \pm 0.21$ \\
\hline 1 & $55.6 \pm 0.34$ & $47.51 \pm 0.72$ & $45.14 \pm 0.37$ & $26.47 \pm 0.74$ \\
\hline 3 & $72.5 \pm 0.36$ & $65.4 \pm 0.23$ & $58.38 \pm 0.65$ & $35.73 \pm 0.36$ \\
\hline 5 & $85.32 \pm 0.54$ & $85.92 \pm 0.34$ & $65.27 \pm 0.36$ & $51.7 \pm 0.23$ \\
\hline 7 & $98.2 \pm 0.71$ & $89.1 \pm 0.56$ & $71.24 \pm 0.54$ & $69.2 \pm 0.54$ \\
\hline 9 & - & $97 \pm 0.23$ & $85.42 \pm 0.43$ & $82.05 \pm 0.36$ \\
\hline 11 & - & - & $97.02 \pm 0.57$ & $94.2 \pm 0.47$ \\
\hline 13 & - & - & - & $96.6 \pm 0.22$ \\
\hline
\end{tabular}

Table 7: Release profile of egg albumin microspheres.

\begin{tabular}{|c|c|c|c|c|}
\hline Time(hrs) & F5 & F6 & F7 & F8 \\
\hline 0 & 0 & 0 & 0 & 0 \\
\hline 0.25 & $1.02 \pm 0.45$ & $3.06 \pm 0.43$ & $21.82 \pm 0.51$ & $20.7 \pm 0.24$ \\
\hline 0.5 & $2.52 \pm 0.64$ & $10.06 \pm 0.65$ & $32.4 \pm 0.35$ & $31.5 \pm 0.35$ \\
\hline 1 & $11.2 \pm 0.54$ & $21.4 \pm 0.56$ & $54.1 \pm 0.19$ & $53.1 \pm 0.49$ \\
\hline 3 & $19.64 \pm 0.45$ & $35.14 \pm 0.72$ & $69.4 \pm 0.72$ & $68.6 \pm 0.59$ \\
\hline 5 & $26.24 \pm 0.37$ & $49.62 \pm 0.37$ & $74.2 \pm 0.45$ & $73.2 \pm 0.35$ \\
\hline 7 & $46.67 \pm 0.26$ & $64.12 \pm 0.57$ & $85.9 \pm 0.36$ & $84.7 \pm 0.66$ \\
\hline 9 & $66.42 \pm 0.54$ & $77.42 \pm 0.55$ & $91.3 \pm 0.65$ & $90.3 \pm 0.73$ \\
\hline 11 & $77.81 \pm 0.65$ & $88.4 \pm 0.29$ & $95.2 \pm 0.52$ & $97.1 \pm 0.43$ \\
\hline 13 & $82.4 \pm 0.19$ & $97.4 \pm 0.45$ & & \\
\hline 15 & $91.42 \pm 0.24$ & & & \\
\hline 17 & $97.1 \pm 0.28$ & & & \\
\hline
\end{tabular}

Table 8: Release profile of sodium alginate microspheres.

3) Percentage of drug release versus square root of time.

4) Square of time versus Percentage of drug release.

From the below plots the kinetic value were calculated and listed in Table 9. The degree of linearity of this plots were tested by applying statistical regression analysis from which correlation coefficient $(r)$ and slope (n) were determined (Tables 9 and 10), (Figures 6-9).

\section{Accelerated stability studies: (Table 11)}

All the values are represented as Mean $\pm \operatorname{SD}(n=3)$

Significant changes were not noticed. The formulation F5 was found to be stable after exposure to accelerated temperature and humidity conditions for a period of 3 months. No significant changes were seen in physical evaluation parameters and in vitro drug release data was given in the Table 11 .

\section{Conclusion}

The present study shows that the microspheres prepared polymer 


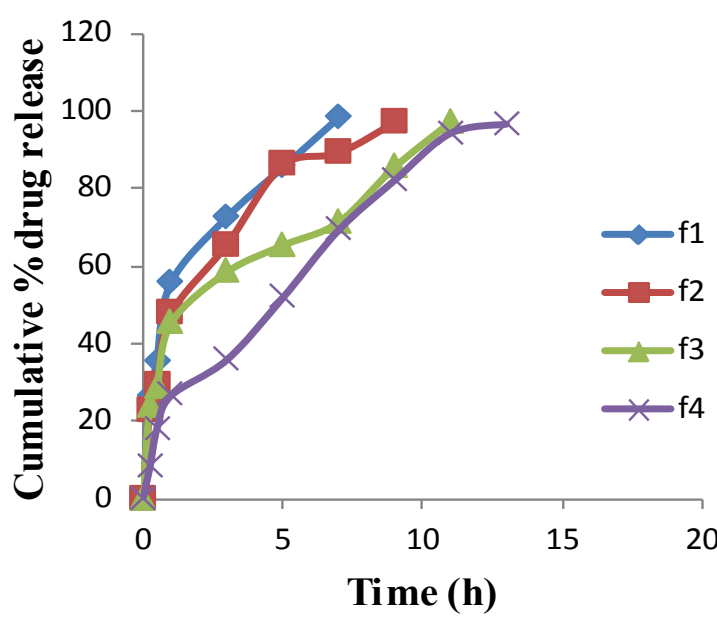

Figure 4: In vitro drug release of famotidine from egg albumin (F1-F4)



Figure 5: In vitro drug release of famotidine from sodium alginate (F5-F8)

\begin{tabular}{|c|c|c|c|c|c|c|}
\hline $\begin{array}{c}\text { Time } \\
\text { (hrs) }\end{array}$ & LOG T & SQRT T & $\begin{array}{c}\text { \% Drug } \\
\text { Release }\end{array}$ & $\begin{array}{c}\text { Log \% Drug } \\
\text { Release }\end{array}$ & $\begin{array}{c}\text { \% Drug } \\
\text { Remained }\end{array}$ & $\begin{array}{c}\text { Log \% Drug } \\
\text { Remained }\end{array}$ \\
\hline 0 & - & 0 & 0 & - & - & 2 \\
\hline 1 & 0 & 1 & 11.2 & 1.049218 & 88.8 & 1.948413 \\
\hline 3 & 0.477121 & 1.732051 & 19.64 & 1.293141 & 80.36 & 1.90504 \\
\hline 5 & 0.69897 & 2.236068 & 26.24 & 1.418964 & 73.76 & 1.867821 \\
\hline 7 & 0.845098 & 2.645751 & 46.67 & 1.669038 & 53.33 & 1.726972 \\
\hline 9 & 0.954243 & 3 & 66.42 & 1.822299 & 33.58 & 1.526081 \\
\hline 13 & 1.113943 & 3.605551 & 82.4 & 1.915927 & 17.6 & 1.245513 \\
\hline 17 & 1.230449 & 4.123106 & 97.1 & 1.987219 & 2.9 & 0.462398 \\
\hline
\end{tabular}

Table 9: Ex-vivo drug release of Famotidine from F5 Formulation.

\begin{tabular}{|c|c|c|c|c|c|}
\hline & & Zero order & $\begin{array}{c}\text { Korsemeyer } \\
\text {-Peppas Model }\end{array}$ & $\begin{array}{c}\text { Higuchi } \\
\text { Model }\end{array}$ & First order \\
\hline Slope & $\mathrm{m}$ & 5.89 & 0.81 & 24.90 & -0.08 \\
\hline Regression & $\mathrm{r}$ & 0.97 & 0.96 & 0.92 & 0.89 \\
\hline intercept & $\mathrm{c}$ & 3.17 & 0.97 & -13.39 & 2.15 \\
\hline
\end{tabular}

Table 10: Kinetic Model fitting data.

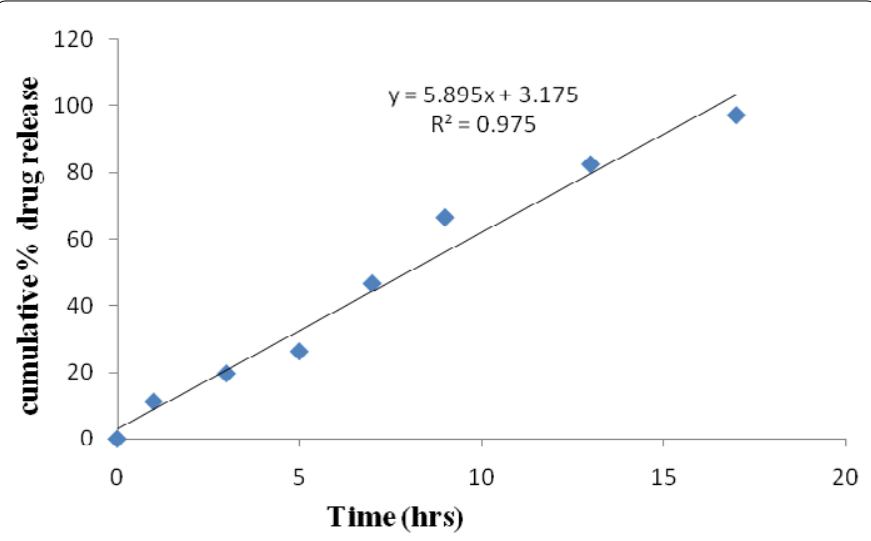

Figure 6: Zero order release rate of Famotidine from formulation F5.



Figure 7: Korsemeyer-Peppas kinetics plot of Famotidine from formulation F5

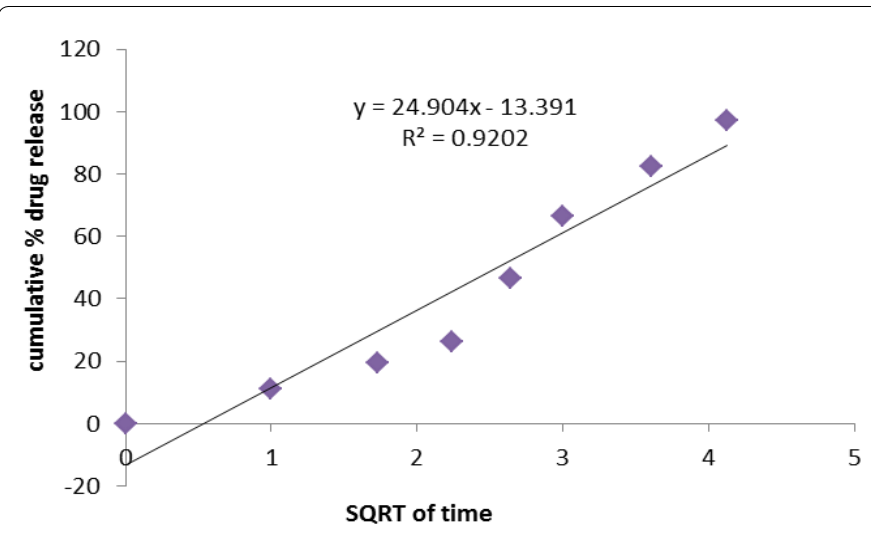

Figure 8: (Higuchi'sPlot) of famotidine from famotidine F5.

sod. alginate and egg albumin both have a significant effect on the mucoadhesion, drug entrapment efficiency and drug release. Egg albumin is hydrophilic polymer has good entrapment efficiency and good mucoadhesion but it releases the drug immediately therefore sod. alginate was used to control the release rate as well as the other factors to match the acceptance criteria. After evaluating all the formulation, the formulation F5 which is containing the higher percentage of egg 
Citation: Shanthi Priya CH (2015) Design and Characterization of Mucoadhesive Microspheres for Gastro-Retentive Delivery of Famotidine Hydrochloride. J Bioengineer \& Biomedical Sci 5: 153. doi:10.4172/2155- 9538.1000153

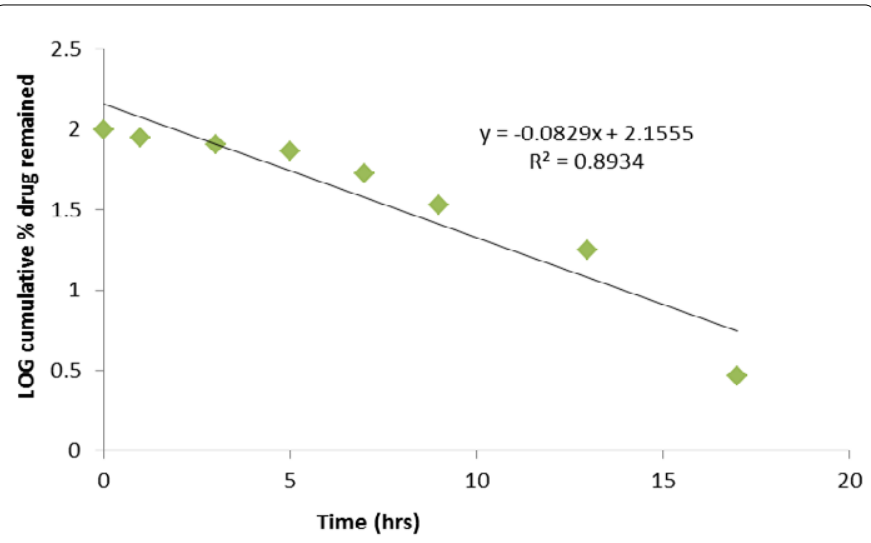

Figure 9: First order release rate of Famotidine from formulation F5.

\begin{tabular}{|c|c|c|c|c|}
\hline \multirow{2}{*}{ Parameters } & \multicolumn{4}{|c|}{ Temperature maintained: $\mathbf{4 0}^{\circ} \mathbf{C} ;$} \\
\hline & $\mathbf{0}$ (Initial) & $\mathbf{1}^{\text {st }}$ month & $\mathbf{2}^{\text {nd }}$ month & $\mathbf{3}^{\text {rd }}$ month \\
\hline Percentage Yield(\%) & $98.64 \pm 0.31$ & $98.63 \pm 0.05$ & $98.55 \pm 0.04$ & $97.88 \pm 0.039$ \\
\hline $\begin{array}{c}\text { Encapsulation } \\
\text { efficiency (\%) }\end{array}$ & $98.00 \pm 0.45$ & $97.98 \pm 0.58$ & $97.45 \pm 0.69$ & $97.32 \pm 0.61$ \\
\hline In vitro wash off test & $71 \pm 0.06$ & $70 \pm 0.01$ & $69 \pm 0.19$ & $68 \pm 0.14$ \\
\hline $\begin{array}{c}\text { In vitro drug } \\
\text { release(\%) }\end{array}$ & $97.1 \pm 0.04$ & $97.0 \pm 0.058$ & $96.88 \pm 0.05$ & $96.70 \pm 0.03$ \\
\hline
\end{tabular}

Table 11: Accelerated stability studies.

albumin showed the good entrapment efficiency about $98 \%$, in vitro wash off test was found to be about $82 \%$ and good drug release profile in $8 \mathrm{hrs}$. Therefore it was selected as the best formulation.

\section{References}

1. James EF, Reynolds (1996) The extra pharmacopoeia / Martindale. Royal Pharmaceutical Society London.

2. Singh B, Kim K (2000) Floating drug delivery systems: An approach to ora controlled drug delivery via gastric retention. J Control Release 63: 235-259.

3. Tripathi KD (203) Essentials of medical pharmacology. (5thedn), Jay Pee brothers: Medical publishers $(P)$ Itd, New Delhi.

4. Kimura K, Ido K, Saifuku K, Taniguchi Y, Kihira K, et al. (1995) A 1-h topical therapy for the treatment of Helicobacter pylori infection. Am J Gastroenterol 90: 60-63.
5. Akiyama Y, Nagahara N, Nara E, Kitano M, Iwasa S, et al. (1998) Evaluation of oral mucoadhesive microspheres in man on the basis of pharmacokinetics of furosemide and riboflavin, compounds with limited gastrointestinal absorption sites. J Pharm Pharmacol 50: 159-166.

6. Yellanki SK, Singh J, Syed JA, Bigala R, Goranti S, et al. (2010) Design and Characterization of Amoxicillin trihydrate Mucoadhesive Microspheres for Prolonged Gastric retention. Int J Pharma Sci Drug Res 2: 112-114.

7. Koner P, Saudagar RB, Daharwal SJ (2007) Gastro-retentive drugs: a nove approach towards floating therapy in drugs: a novel approach towards floating therapy.

8. Arora S, Ali J, Ahuja A (2005) Floating drug delivery systems: a review. AAPS Pharm Sci Tech 6: E372-E390.

9. Rao SB, Sharma CP (1997) Use of chitosan as biomaterial: studies on its safety and hemostatic potential. J Biomed Mater Res 34: 21-28.

10. Akiyama Y, Yoshioka M, Horibe H, Hirai H, Kitamori N, et al. (1993) Nove oral controlled-release microspheres using polyglycerol esters of fatty acids. J Controlled Release 26: 1-10.

11. Kiyama Y, Nagahara N, Kashihara T, Hirai S, Toguchi H (1995) In vitro and in vivo evaluation of mucoadhesive microspheres prepared for the gastrointestinal tract using poly glycerol esters of fatty acids and poly(acrylic acid). Pharm Res 12: $397-405$

12. Axon AT (1994) The role of acid inhibition in the treatment of Helicobacter pylori infection. Scand J Gastroenterol 29: 16-23.

13. Chiba N, Rao BV, Rademaker JW, Hunt H (1992) Meta-analysis of the efficacy of antimicrobial therapy in eradicating Helicobacter pylori. Am J Gastroentero 87: $1716-1727$.

14. Nagahara N, Akiyama $Y$, Nakao M, Tada M, Kitano M, et al. (1998) Mucoadhesive microspheres containing amoxicillin for clearance of helicobacter pylori. Antimicrobial Agents and Chemotherapy 42: 2492-2494.

15. Gennaro AR (1995) Remington: The science and practice of pharmacy. (19 edn), Mack Publishing Company.

16. Donnell PO, McGinity J (1997) Preparation of Microspheres by the solvent evaporation technique. Adv Drug Del Rev 28: 25-42.

17. Rahman Z (2006) Characterization of 5-Fluorouracil Microspheres for Colonic Delivery AAPS Pharm. Sci Tech 7: E-1- E-9.

18. Benita S (1996) Microencapsulation: Methods and Industrial Applications. (2ndedn), Marcel Dekker, New York.

19. Gopferich A, Alonso M, Langer R (1994) Development and characterization of microencapsulated microspheres. Pharm. Research 11: 1568-1574.

20. Jain D, Panda AK, Majumdar DK (2005) Eudragit S-100 Entrapped Insulin Microspheres for Oral Delivery. AAPS Pharm Sci Tech 6: E100-107. 